\title{
Influence of gender on career readiness among Malaysian undergraduates
}

\begin{abstract}
This study aimed to investigate the influence of gender on career readiness among Malaysian undergraduate students at Malaysian universities. Data were collected via a self-administered questionnaire of 1229 Malaysian undergraduate students from four public universities. Respondents were identified through the multistage stratified sampling method. Findings of the study indicate that a majority of the respondents reported low level of career readiness. When compared to male undergraduates, female undergraduates were found to have lower career readiness as manifested by the higher need for career information, and by being more anxious and indecisive when having to make career decisions. An understanding of the factors which contribute to career readiness among male and female university students will help to provide insights for educators in improving students' career developmental process.
\end{abstract}

Keyword: Malaysian undergraduates; Career readiness; Gender 